\title{
Education with BBC micro:bit
}

\author{
https://doi.org/10.3991/ijoe.v16i14.17071 \\ Patrik Voštinár $\left.{ }^{\bowtie}\right)$, Jaroslav Knežník \\ Matej Bel University, Banská Bystrica, Slovakia \\ patrik.vostinareumb.sk
}

\begin{abstract}
Teaching Computer Science in all level of education is not easy, because most students are scared of the programming. Therefore, most of the teachers in Slovak schools prefer to teach special software for a spreadsheet editor, presentation programs, etc. This contribution deals with our experience of using an educational board $\mathrm{BBC}$ micro:bit in the educational process. We will explain some of our prepared tasks for teaching programming concepts, which we used for teaching with BBC micro:bit in primary, secondary schools, and university. In the article, we will also focus on various types of extensions, which could be used together with micro:bit. We will explain the results of our research and look at whether using BBC micro:bit can increase the student's motivation for learning programming.
\end{abstract}

Keywords - BBC micro:bit, programming, computer science, stop:bit, neopixel

\section{Introduction}

Today, digital technologies are a common part of life. Because of that it is important to start teaching these technologies in early life of every children. Computer Science is one of the compulsory subjects in primary and secondary schools in Slovakia. In primary schools, computer science begins to be taught from 8 years. During studying computer science at primary school, pupils have to learn programming basics according to ISCED (The International Standard Classification of Education) in the thematic part Algorithmic Problem Solving. In primary schools, teaching computer science is compulsory 1 hour a week (8-13 years old pupils). Each school has an option to increase these lessons - depends on their focusing (if they want to have more lessons of physical training, chemist, biology, etc.). In secondary schools, teaching of Computer Science is very similar to primary schools. It is compulsory during whole four years of their study within the range three lessons a week. It is up to each school, to which year of study they want to include these compulsory lessons. Each school can also have optional lessons of Computer Science.

The State Education Program does not prescribe use of any particular programming environment. The teacher can choose the environment that suits him / her. There is also something what teacher cannot choose, he /she has to use the Slovak language programing environment, possibilities of the environment and methodological support. In 
primary schools, it was used programming languages Baltík and Imagine Logo1. Nowadays the most used programing language at Slovak primary schools is Scratch2, while secondary schools prefer Python. Teaching with programming languages, such as Scratch, Python is more popular and best for programming starting, but for some students is not motivational enough. The solution could be using motivational hardware such as Lego Mindstorms EV3, Sphero, Ozobot robots, etc. Physical computing in cooperation with a block-based environment have become more and more attractive, especially for presenting programming to young students - beginners [1]. The main problem with these robots is their price.

In a wave of devices that may have started with the Raspberry Pi, there are now dozens of small, powerful devices, ranging in price from a few dollars to a few hundred dollars. Various technology companies have been quietly releasing smaller, lower power chips and devices in the background. [2]

Currently it is very popular and cheap educational board BBC micro:bit. Its biggest advantage is a minimal cost, highly functional board to help teaching.

\section{BBC micro:bit}

BBC micro:bit (Fig. 1) is what is technically known as a microcontroller development board. It's a printed circuit board (PCB) which contains a microcontroller on which it is possible to run own programs and connect own hardware. [3]

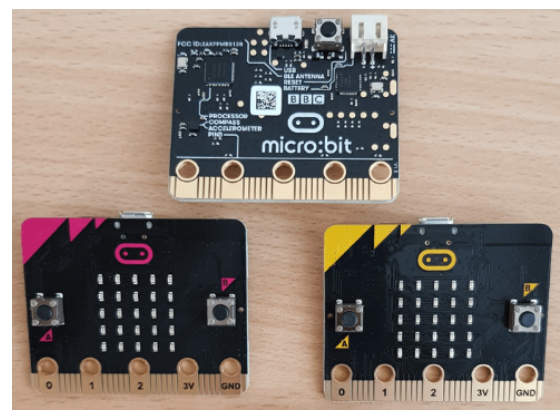

Fig. 1. BBC micro:bit

Another description of BBC micro:bit could be a tiny, pocket-sized physical device, which consists of programmable computer and small battery which powers the circuit board. It is designed to make learning and teaching younger audience. [4].

It is low-cost device, that was assigned to each 11-12 years old pupil in the UK in 2016 [5]. Independent research tracked the progress of the BBC micro:bit in the UK during its first year of its deployment and found, that $85 \%$ of teachers who used this

${ }^{1}$ http://www.statpedu.sk/sk/svp/statny-vzdelavaci-program/

${ }^{2}$ http://imagine.input.sk/

${ }^{3}$ https://scratch.mit.edu/ 
device agreed, that it makes Computer Science more enjoyable for their students, and $90 \%$ of the children who used it said it helped to show them ,that anyone can code [6].

In comparison with more sophisticated piece of hardware (such as Arduino and Raspberry), BBC micro:bit is powerful even without any extensions.

It can be used to teach programming and computing concepts to children of any age. It can be programmed by block-based language, JavaScript, $\mathrm{C}$ and MicroPython.

Fig. 2 shows online editor MakeCode created by Microsoft. In case you want to use the offline version of this editor, it is available for free from Microsoft Store. The primary goal of MakeCode is to teach programming with a block-based programming language. For users, that are familiar with blocks and how they work, they can switch to coding more complex programs in the scripting language JavaScript, which is mostly used for programming webpages or MicroPython. Fig. 2 shows block-based programming in the MakeCode. Fig. 3 shows programming in JavaScript language.

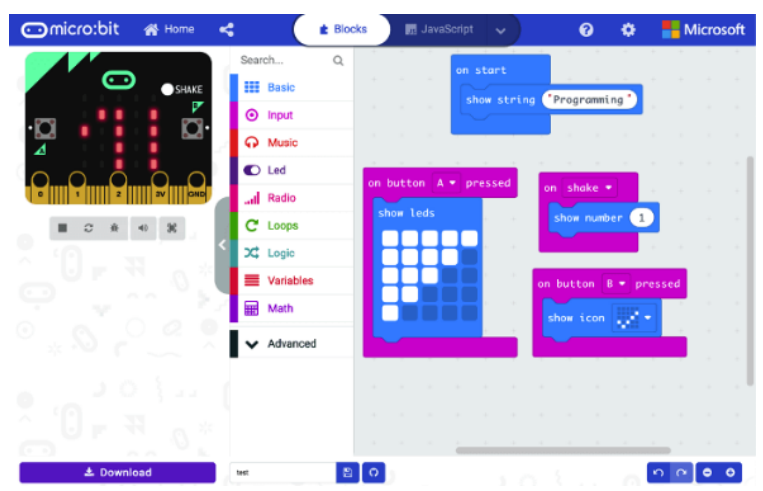

Fig. 2. The MakeCode editor - block-based programming

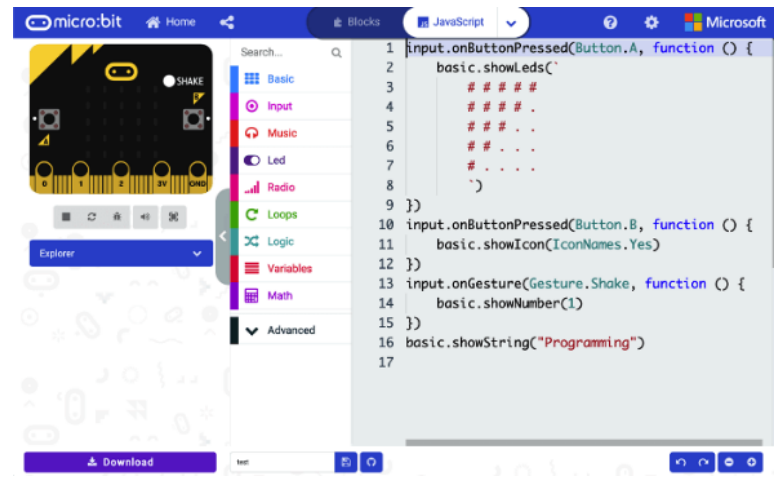

Fig. 3. The MakeCode editor - JavaScript

Fig. 4 shows programming in MicroPython, which is the latest innovation. You can switch between these languages using the buttons in the top bar. MakeCode editors contain simulator, which can be used for displaying the result of code without physical educational board BBC micro:bit. 
For running code in $\mathrm{BBC}$ micro:bit it is important to press the button Download (at the bottom) and to copy generated file (with extension. hex) to BBC micro:bit. After $\mathrm{BBC}$ micro:bit is connected to a computer via USB cable, special disc appear in your computer (copy the file like to USB key).

The user can create some code in a block language and then see what it looks like in JavaScript or MicroPython.

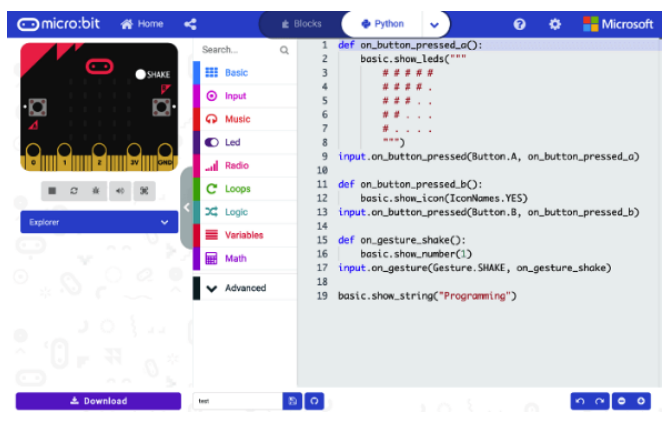

Fig. 4. The MakeCode editor - MicroPython

\section{$3 \quad$ Methodology and Results}

Our research was held at the beginning of the school year 2019/2020. In our research we used BBC micro:bit for teaching Computer Science in primary school ZŠ Ďumbierska (Banská Bystrica, Slovakia) and in two secondary schools - Gymnázium Milana Rúfusa (Žiar nad Hronom, Slovakia) and Stredná odborná škola technická (Zvolen, Slovakia). The main aim of our research was to find out, whether we can motivate students to study Computer science by using BBC micro:bit. We used the questionnaire for measuring data of our research. We asked 28 primary school students and 36 high school students several questions in the questionnaire. The questionnaire filled 26 girls and 38 boys. The research using BBC micro:bit was based on the school directors' initiative. They wanted to motivate their students to continue with teaching computer science. In Gymnazium Milana Rúfusa were students selected according to their interest to continue with using BBC micro:bit. In the other two schools were students selected by their computer science teacher. For this reason, there weren't any control groups in the schools.

First question after the gender selection was focused to whether they know (remember), what is micro:bit. Most of them wrote, that it is interesting hardware for programming.

Question Did these activities make sense to you? was aimed to whether they know, that using BBC micro:bit it's not only for playing in the Computer Science lesson. $73,4 \%$ students says, that it make sense (yes, rather yes) to program BBC micro:bit in the lessons (Fig. 5). 


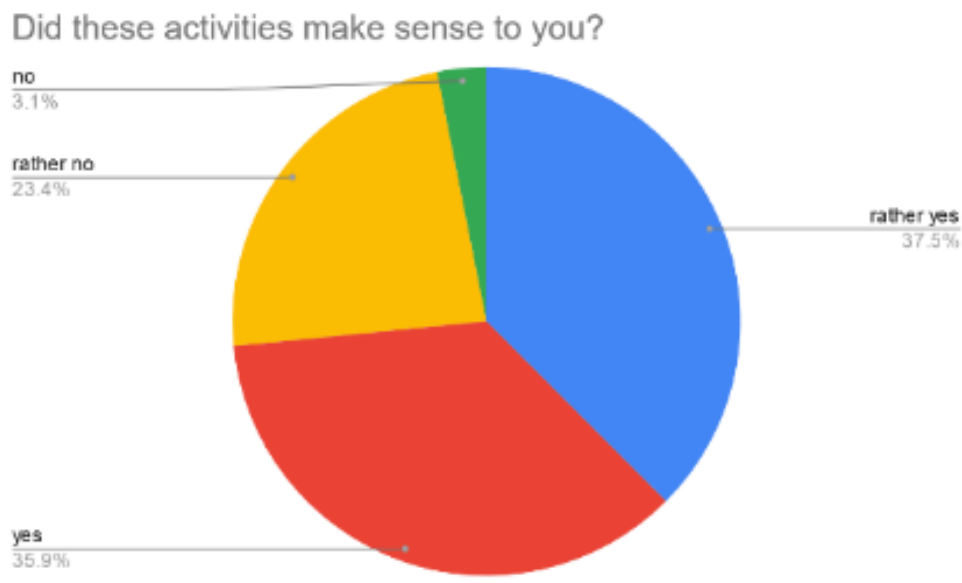

Fig. 5. Did these activities make sense to you?

Question Did you like lessons with micro:bit? Results from this question show that $89,10 \%$ students like these lessons (Fig. 6). This particular finding was very important to know that we should continue with teaching programming with $\mathrm{BBC}$ micro:bits.

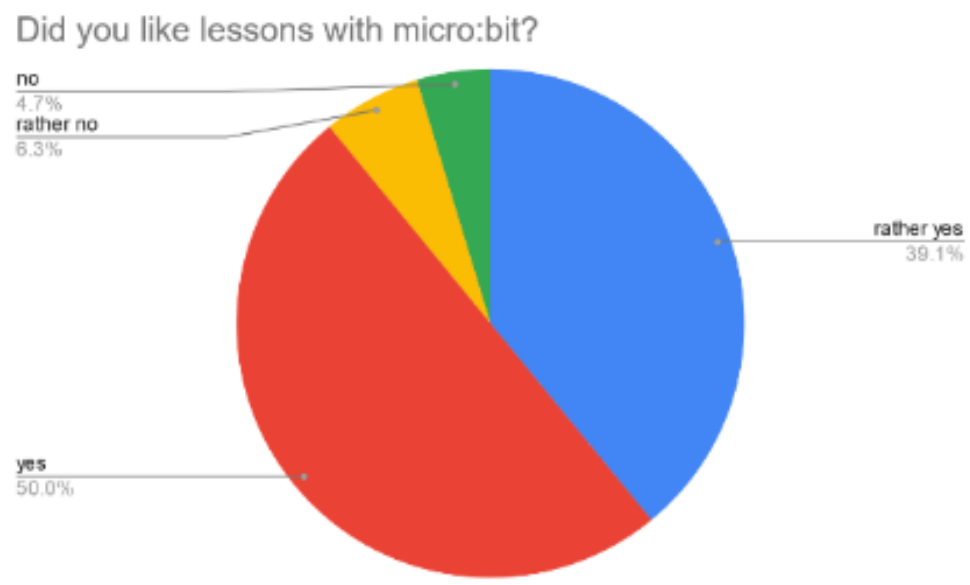

Fig. 6. Did you like lessons with BBC micro:bit?

$25 \%$ students in question Were the lessons difficult for you? wrote, that it was. For more students, it isn't difficult to program something in BBC micro:bit (Fig. 7). 


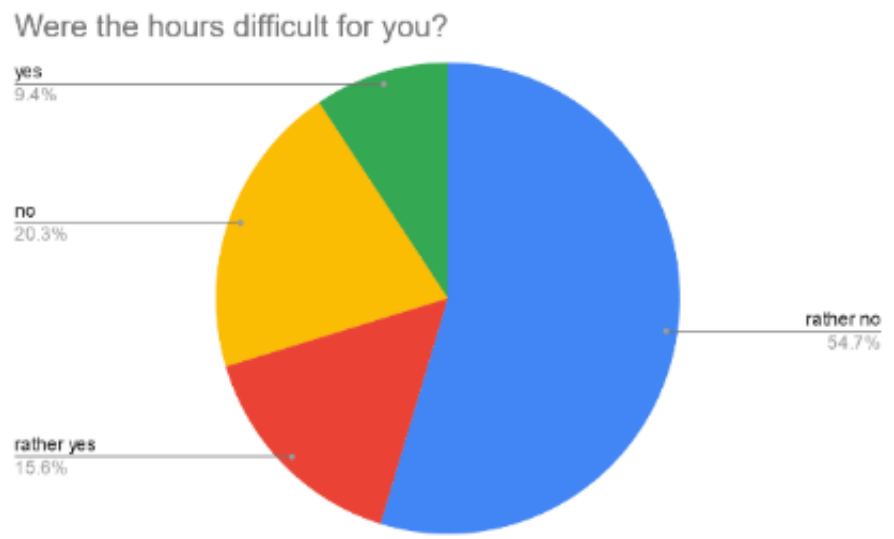

Fig. 7. Were the hours difficult for you?

$66,6 \%$ students would like to continue programming with BBC micro:bit (Fig. 8). This question is similar to question Did these activities make sense to you? The results are also similar. According to the results, we assume that students want to use BBC micro:bit.

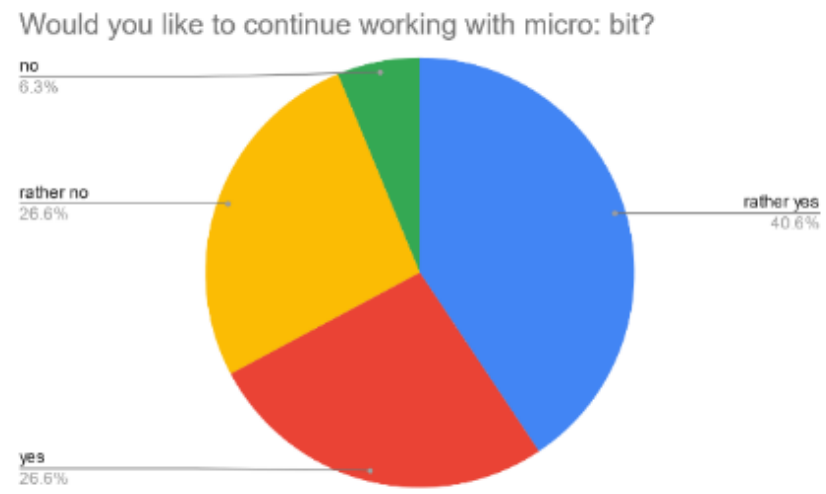

Fig. 8. Would you like to continue with BBC micro:bit?

\section{$4 \quad$ BBC micro:bit Tasks}

We prepared the various types of tasks for BBC micro:bit. All participants already had some previous experience with Scratch block environment, these experiences were useful for them. In primary school, we started with basic coding - task with using variables, cycles, functions, radio communication, etc. 
Example of tasks:

- Events - after pressing buttons A, B, A+B, shake micro:bit, etc. Micro:bit LEDs matrix (5x5) display various icons (heart, yes/no, happy, t-shirt, etc.), texts, numbers, arrows.

- Math - after shaking micro:bit will display random number (dice), to use $\min / \max$ value, round, etc.

- Simple games with storing data in variable or array (increase, decrease number after some events), rock-paper-scissors.

- LED light - led connected via crocodile clips and resistors.

- Wireless communication - sending text/number through micro:bit to another micro:bit.

All tasks and teaching materials are available on our webpage3.

Fig. 9 shows using BBC micro:bit in teaching process in primary school ZŠ Ďumbierska (Banská Bystrica, Slovakia).

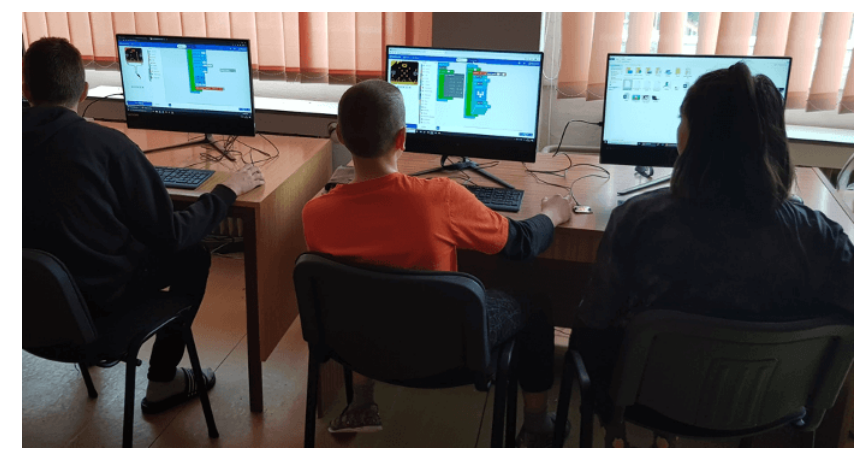

Fig. 9. Using BBC micro:bit in Z ̌̌ Ďumbierska

For teaching we also used an additional extension for micro:bit such as speakers, Neopixel LED strips, stop:bit.

\subsection{Neopixel LED strip}

Neopixel LED Strip is a colorful strip based on WS2812B beads, it can display color of RGB and support cascade at the same time (Fig. 10).

${ }^{3}$ http://www.fpv.umb.sk/katedry/katedra-informatiky/informaticky-kruzok-umb-preziakov-zs-a-ss/materialy-k-vyucbe-pre-zs.html 


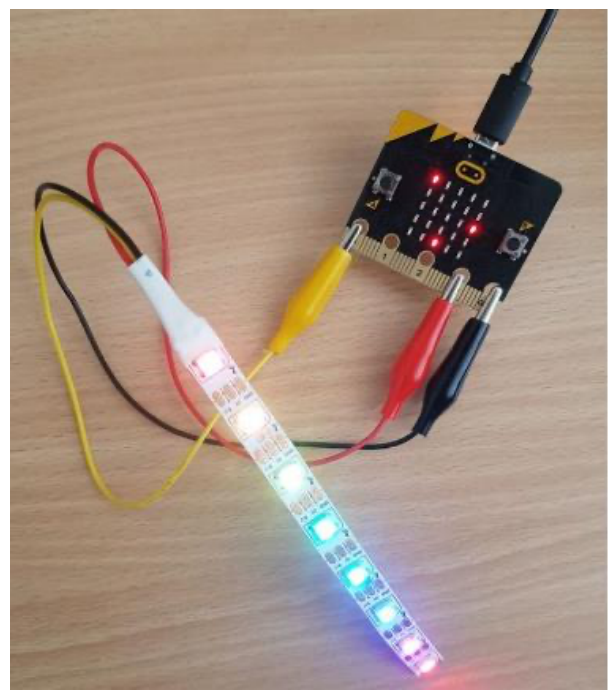

Fig. 10.Neopixel extension

Working with Neopixel Strip has many advantages. Using crocodile clips students connected Neopixel to micro:bit and operated it. As a main benefit of this extension we consider the ability to use micro:bit's pins. Students learnt that they need data pin to transfer data from micro:bit to neopixel, a power pin and a pin that works like the ground.

Example of tasks for Neopixel strip:

- Create program, that will display red color on all leds, wait 1 second, display blue color, wait 1 second, display purple color, wait 1 second, display indigo color, wait 1 second, display orange color.

- For each LED in strip set different color (use loops and array).

- After shake micro:bit display random color for each LED.

- In block forever program changing 5 colors, between showing colors set wait block (use variable, for initialized value use $100 \mathrm{~ms}$ ). If the button $\mathrm{A}$ is pressed, do an addition of this time to $+100 \mathrm{~ms}$. If the button $B$ is pressed, do subtraction of this time to $-100 \mathrm{~ms}$ (Fig. 11). 


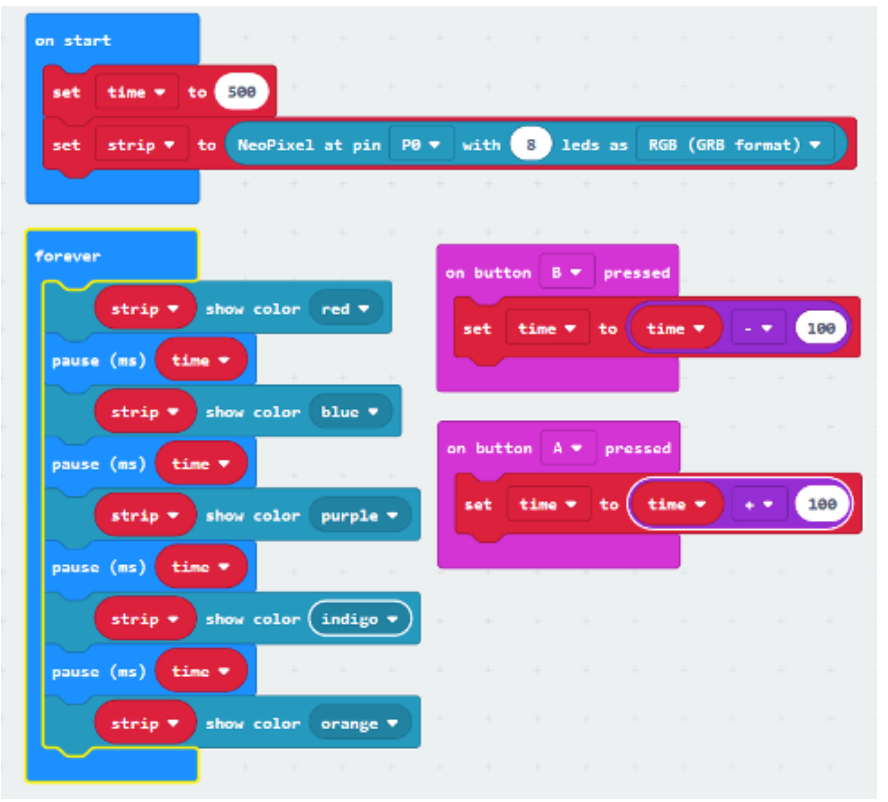

Fig. 11. Neopixel extension - code

To find out if the programming of the LED strip is interesting for students, we asked a question in our questionnaire research How do you evaluate the work with LED strip? Based on the results - most of them say they like programming LEDs ( 5 students dislike, Fig. 12). Using neopixel strip with BBC micro:bit was for the students very motivated. They have no problem to solve tasks with neopixel strip. The disadvantage of these tasks was, that many of them wanted to play more with neopixel strip.

How do you evaluate the work with LED strip?

64 responses

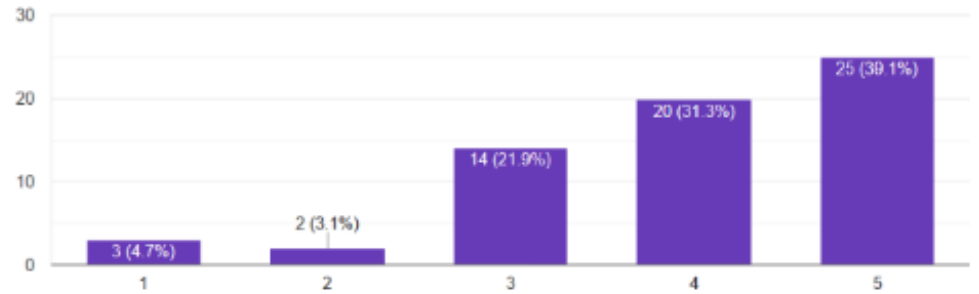

Fig. 12. How do you evaluate the work with LED strip? 


\subsection{Speaker}

Another type of extension was very cheap one - to use speaker (wired, should have $3,5 \mathrm{~mm}$ JACK) and two crocodile clips. The speaker connector had 2 metal strips for left and right speaker, the third connector strip is for ground (Fig. 13).

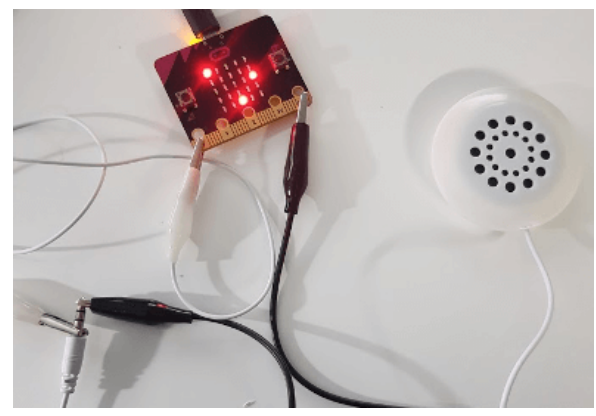

Fig. 13. BBC micro:bit with speakers

Example of tasks for extension- speaker:

- Create melody from offered options.

- Create own music via tones.

- Slovak national anthem.

For these types of tasks, music category micro:bit uses is considered the most valuable learning value. Students have learned to work with a musical scale to recognize tones and put them together into melodies to fulfill the purpose of the task.

Similar to Neopixel LED strip, we want to find out if programming of the Speaker was interesting for students. We asked students How do you rate the work with SPEAKER? Results were interesting, most of them choose neutral answer (Fig. 14). Solving tasks for micro:bit connected to the external speaker was not for students so interested, then working with neopixel strip. The main problem was for the students who have a little knowledge of music tones. They had to found and understand what does it mean Middle G, Middle A, etc. In each school, there were students who helped others with understanding music tones.

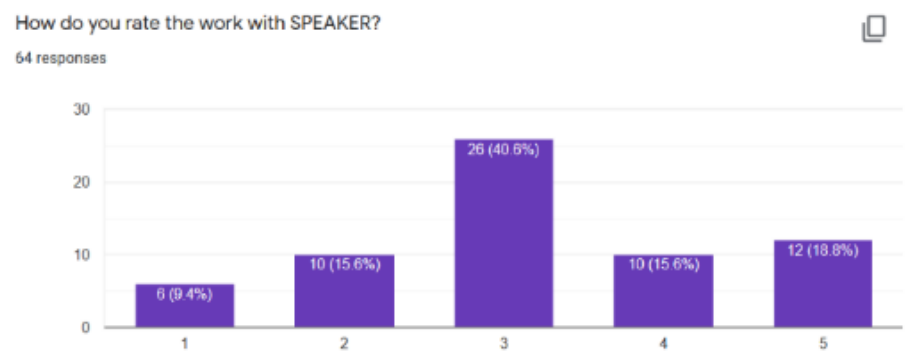

Fig. 14. How do you rate the work with speaker? 


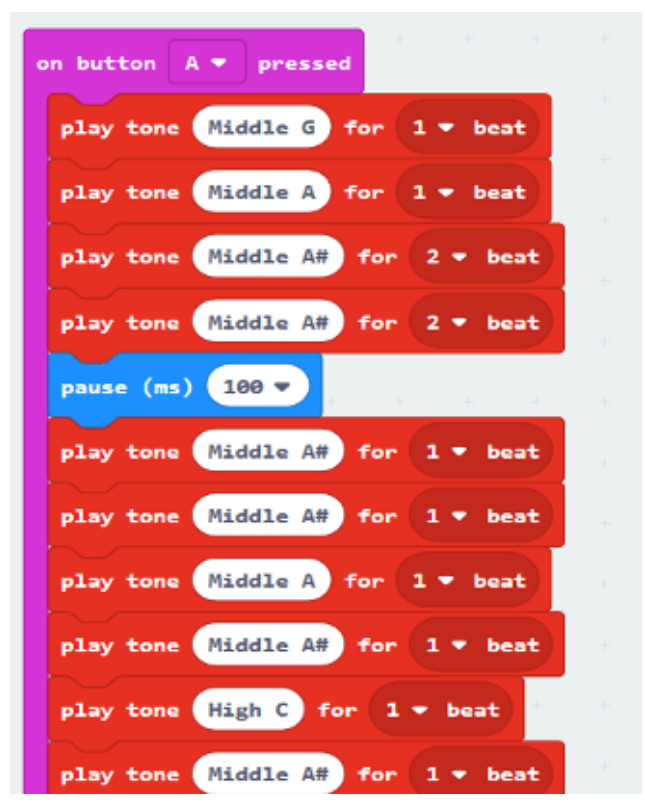

Fig. 15. BBC micro:bit with speaker - code

\subsection{Stop:bit}

Stop:bit is a very simple extension for micro:bit which symbolizing traffic light (Fig. 16). It basically consists of two pieces, first one is a connected micro:bit by 4 screws which are not easily removed, so it makes looks stop:bit as a one whole piece. Alternatively, it can also be connected by crocodile clips. The second piece are 3 Led diodes, each on is driven from one micro:bit pin.

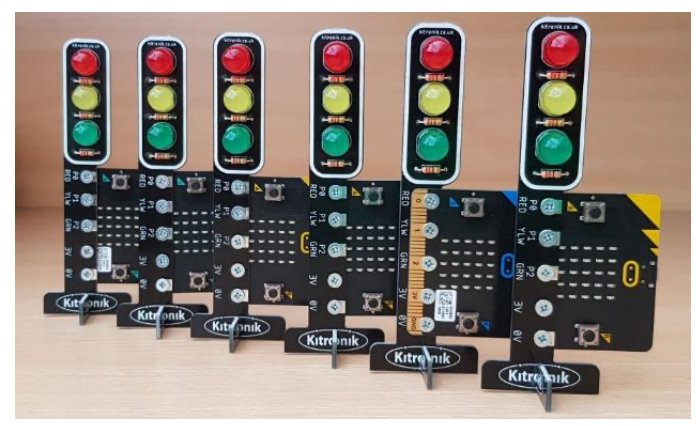

Fig. 16. Stop:bit

To usual programing environment Microsoft Makecode can be added as an extension 'kitronik-stopbit', where it has own blocks for easier configuration.

Stop:bit can be used in many activities e.g.: 
- As a single traffic lights next to pedestrian crossing or using multiple of these pieces as network of traffic lights for managing city.

- As a shower of any values which has 2 or 3 states in many interesting activities, e.g. 'Quiz'.

- As a shower of music rhythm.

- In activities where we need traffic lights, but we do not have time to make our own from diodes and resistors in breadboard, or when we just need it to look nice and fits to surroundings.

- Anywhere where its diodes could be useful.

Task 1 - radio communication and turns green/red light: Student uses radio function and sends a string to stop:bit. Stop:bit distinguishes between received messages and displays color according to received string. Stop:bit after receiving text ,green“ turns on the green light, after receiving text „red” - turns on the red light.

Micro:bit on pressed (Fig. 17):

- Button A - sends text message ,, green”.

- Button B - sends text message ,red”.

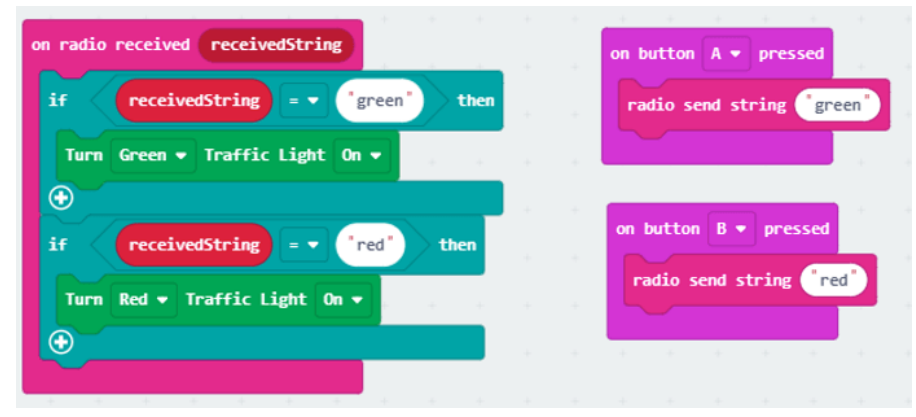

Fig. 17. radio communication and turns green/red light

Task 2 - math quiz show: Student answers the questions, said, or displayed on blackboard. Teacher sets the correct answer through his micro:bit. Using micro:bit radio function student sends answer through his micro:bit to solver micro:bit, which turns on the light according to answer correctness. Solver compares the answer with value received from teacher.

When message is received (in stop:bit) sets the variable:

- "Answer" to number, received through radio function in type of number.

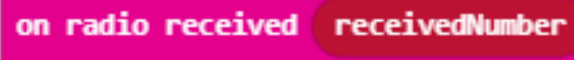

- "Correct" to number, received through name and value of variable in type of variable. 


\section{on radio received name value}

Then compares both variables. If are variables same, turns on green light, otherwise turns on red light.

\section{Micro:bit actions}

- If A button is pressed increments answer by 1 .

- If $\mathrm{B}$ button is pressed decrements answer by 1 .

- If $\mathrm{A}+\mathrm{B}$ buttons are pressed sends answer

Task example:

"How much is 9* 5-31?"

Task description (Fig. 18):

Teachers micro:bit - sends answer in type of name and value of variable ,correct $=$ 14.'

Students micro:bit- sends answer in type of number ,14."

Micro:bit solver - compares answers and turn on green or red light.

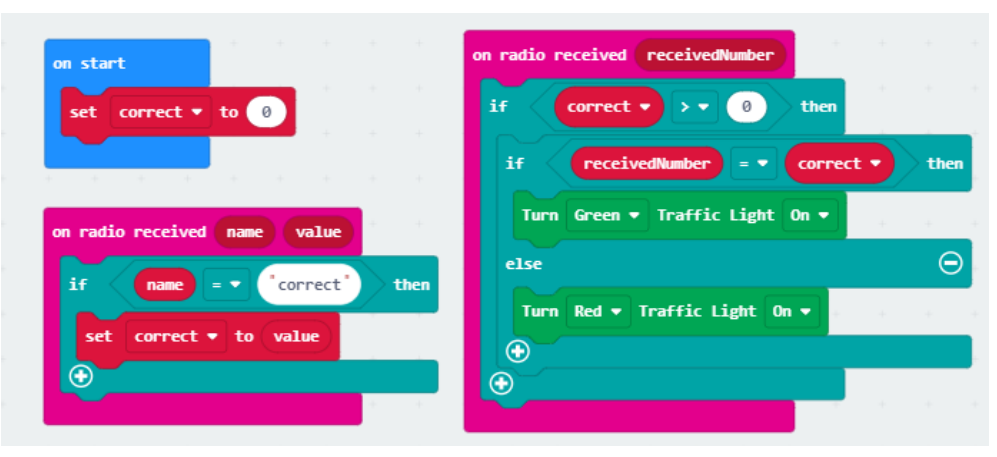

Fig. 18. Math quiz show - Source code

\section{Conclusion}

By this article we wanted to point out the main advantages that BBC micro:bit possess and his huge benefit for teaching Computer Science in all level of education. BBC Micro:bit, as one of the most interesting hardware devices is an excellent opportunity to develop programming skills and algorithmic thinking of students. Thanks to its low cost, brings a lot of music for a little money.

Our research so far has shown that students liked lessons they work with BBC micro:bit and consider this work to be interesting and meaningful.

Besides students consider work with BBC micro:bit as interesting, it can provide them various knowledge, they can use ether in different block environment. 
In this article we also focused on various type of extensions, which could be used together with micro:bit. We described tasks with Neopixel LED Strip, Speaker and extension called stop:bit.

\section{Acknowledgement}

This contribution has been processed as part of the grant project Interactive Applications for Teaching Mathematics at Primary Schools, project no. 003TTU-4/2018 and Implementation of Blended Learning into Preparation of Future Mathematics Teachers and Future Computer Science Teachers, project no. 001UMB-4/2020.

\section{$7 \quad$ References}

[1] Jin, K. H., Eglowstein, H. and Sabin, M., Using Physical Computing Projects in Teaching Introductory Programming. Proceedings of the 19th Annual SIG Conference on Information Technology Education (SIGITE '18), ACM, 2018, New York, USA. pp. 155-155. https://doi.org/10.1145/3241815.3241879

[2] Donat, W., Getting Started with the micro:bit, Maker Media Inc., San Francisco, 2017

[3] Halfacree, G., The official BBC micro:bit. John Wiley \& Sons, Inc., India polis, Canada.

[4] Klimeková, E., et al., Case Study on Physical Computing with Node MCU on Summer School. International Conference on Robotics and Education RiE 2017, 2018

[5] Sentence, S., Waite, J., Yeomans, L. and MacLeod, E., Teaching with physical computing devices: the BBC micro:bit initiative. Proceedings of the 12th Workshop on Primary and Secondary Computing Education (WiPSCE '17), Erik Berendsen and Peter. https://doi.org/10.1145/3137065.3137083

[6] Hubwieser (Eds.). ACM, 2017, New York, NY, USA, 87-96.

[7] Merkouris, A. and Chorianopoulos, K., Programming touch and full-body interaction with a remotely controlled robot in a secondary education STEM course. Proceedings of the 22nd Pan-Hellenic Conference on Informatics - PCI 18, 2018. https://doi.org/10. $\underline{1145 / 3291533.3291537}$

\section{Authors}

Patrik Voštinár is a lecturer, who is working at the Matej Bel University, at the Faculty of Natural Sciences, Department of Computer Science. He teaches subject such as programming web pages (HTML, CSS, JavaScript), creating mobile applications (programming Android, iOS application), discrete mathematics. He is member of two national projects aimed to using information and communication technologies in the education process (mLearning and eLearning). Email: patrik.vostinar@umb.sk.

Jaroslav Knežník is a master's degree student at the Matej Bel University, at the Faculty of Natural Sciences, Department of Computer Science. He is very active in preparing teaching materials for primary school children. Email: jaroslav.kneznik@student.umb.sk.

Article submitted 2020-07-15. Resubmitted 2020-08-22. Final acceptance 2020-08-23. Final version published as submitted by the authors. 